\title{
The Reason We Marry: Perceptions of Women's Sexual Experiences in Zimbabwe
}

\author{
Maxwell C.C. Musingafi ${ }^{1} \quad$ Racheal Mafumbate $^{2} \quad$ Thandi F. Khumalo $^{3}$ \\ 1.Zimbabwe Open University, Department of Development Studies, Faculty of Applied Social Sciences \\ 2.University of Eswatini, Department of Educational Foundations and Management, Faculty of Education \\ 3.University of Eswatini, Department of Sociology and Social Work, Faculty of Social Sciences
}

\begin{abstract}
This study is an interrogation of views and experiences of sexual encounters of women from affluent urban settings and those from traditional communal areas in the communities of Zimbabwe. The study is based on women only WhatsApp groups discussions on their sex lives. Using evidence from the sentiments, views, perceptions and experiences of women from the two different settings, this paper argues that women enjoy heterosexuality; their only problem is that their male colleagues do not perform up to their expectations. This state of affairs makes some segments of feminist scholars think that heterosexuality puts women in a perpetual subordinate position that reduces them to the mothering roles linked to their reproductive capacities. Nonetheless, the female voices in this study argue that although in some cases, they still experience oppression and dissatisfaction women in heterosexual relations have agency and capacity to assert themselves and control their sexual experiences so that they also enjoy sex to optimum levels. The study shows that women are not always passive participants within heterosexual relations for they are able to express their sexual desires freely and sometimes negotiate options for pleasurable sexual experiences. The study shows that heterosexuality is neither a hegemonic nor monolithic one size fits all experience, but a multifaceted heterogeneous experience in which both women and men negotiate their cases in their own special ways.
\end{abstract}

Keywords: Sex, women, sexuality, affluent suburbs, communal areas, perceptions, experiences.

DOI: $10.7176 /$ RHSS/9-8-10

Publication date: April $30^{\text {th }} 2019$

\section{Introduction}

In Zimbabwe, sex is only acceptable and respectable in the heterosexual marriage institution. Thus, although sex is largely a biological and natural need (not only for procreation, but also for silencing some internal agitation), sex is something that should occur only within the boundaries of the socially approved heterosexual marriage institution. In Zimbabwe, emphasis is on both procreation and sexual pleasure for both sexes, as both husband and wife should have unlimited access to sex with their spouse. The phrase, 'Handina kuvinga sadza, ndakavinga murume' (I did not come here for food, but my husband) is full evidence that the popular claim that sexual pleasure is not for wives but husbands is false. It is the duty of both husband and wife to satisfy sexual needs of the spouse. Among the Remba of Zimbabwe, if the wife indulges in extra-marital affairs it is the husband who is blamed for failing to satisfy the wife's sexual needs.

This paper starts with an orientation and contextualization of the problem at hand through giving some background information and arguments on sexuality and sexual experiences from a global human race perspective. By human race perspective, we mean that nothing has one single and well-defined answer in human life. A plethora of interventions stops human beings from having one scientific answer to their everyday experiences and problems. We then articulate the study problem and study methodology before presentation of findings, conclusions and recommendations.

\section{Orientation of the study problem}

This study focuses on sexual experiences and perceptions thereof for women in heterosexual relationships in Zimbabwe. Whether from a biological or social point of view, sexuality has been recognized as central in people's lives. Mapuranga (2019) believes that sexuality is multifaceted and as such it is influenced by biological, cultural, ethical, legal, historical, religious, and spiritual factors. She further quotes the World Health Organization (2004), which claims that "sexual health requires a positive and respectful approach to sexuality and sexual relationships, as well as the possibility of having pleasurable and safe sexual experiences, free of coercion, discrimination and violence. For sexual health to be attained and maintained, the sexual rights of all persons must be respected, protected and fulfilled" (Mapuranga, 2019).

Sexuality has been simply defined as sexual orientation (Peta, 2015). The most common, legal and acceptable sexual orientation among Zimbabwean cultures is heterosexuality (Epprecht, 1998; Zinanga, 1996). Heterosexuality is a relationship where male and female individuals have conventional sex for either procreation or pleasure (Zinanga, 1996). All other sexual orientations are neither legally nor morally acceptable in Zimbabwe (Epprecht, 2013; Government of Zimbabwe, 2013). This however, does not mean that the other orientations like 
homosexuality, lesbianism, bestiality, masturbation, among many others, do not exist in Zimbabwe (Epprecht $(1998,2013)$. Perhaps the only observable major difference between heterosexuality and these other forms of sexuality is that they are just for pleasure not procreation, making them culturally and morally unacceptable. It thus follows that the acquisition of a husband and having children within the parameters of a heterosexual marriage awards women respect within families and communities (Zinanga, 1996). If sex is about procreation and women with disabilities are assumed incapable of making children, it follows that they are denied the pleasures associated with the sex and reproductive processes (Mapuranga, 2019). Mapuranga further argues that the existence of several sexual orientations as determined by biological, cultural, ethical, legal, historical, religious, spiritual, among other factors, shows that sexuality is not simply about vaginal nor anal penetration by a penis. She argues that disabled women who may not be penetrable due to the nature of their disability can still enjoy sex through appropriate forms of sexuality. This, however, may not be legally possible in Zimbabwe where the only acceptable sexual activity is where men and women have conventional sex.

Some feminist scholarship sees sexuality as a political struggle between patriarchal dominance and the search for pleasure and freedom (Butler, 1990; Vance, 1992; Fausto-Sterling, 2003; 2005; Amfred, 2004; Singh, 2013). Feminist literature from varied contexts suggests that within heterosexual relations, female sexual desire and pleasure are controlled and reduced to women's conventional mothering roles linked to their reproductive capacities (Muhanguzi, 2015). According to Amfred (2004) in Africa, sexuality is constructed within a dominant patriarchal context of political struggles for the creation and preservation of gender hierarchy, which defines men as active and dominant and women as passive and submissive. Such constructions marginalise female sexual aspects of pleasure and desire. According to Singh (2013), men and women are entrapped within gendered discourses of romantic love that restrict them from exploring alternative positions in marriage, and they largely comply with existing gender regimes that perpetuate gender inequalities and place women in subordinate positions. For Bhana (2013), affection, desire and intimacy are key to power dynamics and gender relations in relationships. Literature further indicates that women in poor communities living under difficult conditions rarely have a desire for sex and experience greater control and regulation of their sexuality (Maitra and Schensul, 2002). Economic inequality is blamed for inhibiting women's freedom to build loving relationships (Bhana, 2013).

Heterosexual experiences of men and women have been said to be different. For Ingraham (2002) the naturalization of heterosexuality is fake, a ploy to stop women from querying heterosexuality injustices. The naturalization of heterosexuality is just imaginary; it does not exist at all. It is an artificial creation for the benefit of men at the expense of women. For Bernard (2002), there are two marriages; 'his and hers and his is better than hers'. Her argument is that heterosexual marriages and penetration are always good for men and bad for women because they are designed to serve the interests of men. Langford (2002) argues that love has degenerated into heterosexual penetration and relationships, which are based on hypocrisy. She argues that this type of love disappears with age of marriage and women simply give in to sex not because they enjoy it but because it is an obligation for them to keep the marriage institution alive. They become some sacrificial lamb to ensure that the marriage survives. In fact, the marriage institution is based on false foundation as men tend to be dishonesty. They want sex more than the person herself (Langford, 2002). Duncombe and Marsden (2002) believe that in heterosexual relationships women fake orgasm, sexual activity declines and romance fades with time. In fact, the experiences of men and women are world apart. Holland, Ramazanoglu and Thompson (2002) report that men and women in heterosexual penetration and relationships seem to be sailing in the same boat, yet they are sailing in different boats even in their first heterosexual encounters. Sometimes women simply give in to sexual penetration to please men (Holland, Ramazanoglu and Thompson, 2002). The argument is thus heterosexuality might be paradise for men but in fact hell for women. This explains the gap between orgasm in men and that in women. While men are busy enjoying themselves, women are busy crying and lamenting their plight, the argument goes.

Although accepting the thesis that sexuality maybe one of the centres of women's oppression, some feminist scholars believe that power inequality in relationships does not automatically exclude enjoyable and pleasurable sexual experiences (Jackson, 1996; Shefer and Foster, 2001; Bhana, 2013). They argue for recognition of differences in women's experiences and note that the power hierarchy embedded in heterosexual relationships is not necessarily exercised uniformly and evenly at the level of interpersonal relations or practice, nor is its experience wholly determined by patriarchal structures and ideologies (Shefer and Foster, 2001; Bhana, 2013). For some feminist scholars penetrative sex with men can be enjoyable; its pleasure for women is not merely eroticised submission (Segal, 1994; Van Every, 1996). Bhana (2013) agrees with Hirsch (2007) that relations should not only be perceived in terms of male power; men and women as gendered persons express love alongside the daily battles of power. For Rasool (2013) women have capacity to contest and shape their lives as they reflect on violent love. Therefore, women are not just victims of romantic love but find spaces to negotiate their identity, as they navigate their economic circumstances (Herlihy, 2013).

\section{Statement of the problem}

The above orientation has shown that men and women experience heterosexuality differently. It showed that the 
power dynamics in heterosexuality are tilted in favour of men. However, the key question is on whether women feel an inside urge or appetite for heterosexual penetration or it is something they just have to endure to survive the turmoil of heterosexual relationships. How exactly do women in heterosexual unions define sexual desire and pleasure? To what extent are women in heterosexual relationships passive objects with little or no decision-making powers?

\section{Research methodology}

This study is qualitative based on two women only WhatsApp groups' discussions on their sex lives. The two women only groups were different in that one was composed of high-class women in low-density suburbs of the big cities and the other one was more of the communal women of rural Zimbabwe. Whereas the affluent group was relatively homogeneous in terms of class definition (women in low-density areas), the communal rural areas group was heterogeneous in that it included villagers, rural professionals (teachers, nurses, extension workers), traders, among others. Members of the two groups who provided primary data for this study were from one of the researchers' class of the Master of Science in Gender and Policy Studies. For ethical reasons, no names or phone numbers were provided so that even the researchers themselves did not know who the participants were other than the two assistants who provided data from the two groups. For easy communication and identification of the different participants, the assistants were instructed to give these hidden participants code / pseudo names. Both groups were composed of more than 75 members although not everyone participated in the discussions. The research assistant would advise fellow members that she was doing research on her studies assignment. She would then initiate the discussion, so that as usual members came in with their experiences and perceptions. The discussions were on three questions:

- As a woman, how do you communicate your sexual feelings to your male partner?

- Can you survive without sex?

- Is your male partner taking you through to orgasm?

\section{Findings}

The study established that women put great value to sexual attention from their male partners, whether husband, sugardad or boyfriend. Their argument is that, they entered the heterosexual unions because they wanted the male partner (penetration). Were it not for penetration they would not have bothered themselves starting new life with a stranger. Why marrying a stranger when they already had more than enough relatives? They would have stayed with their relatives back home.

We now present and discuss what they said about their sexual experiences starting with how women communicate their sexual feelings and desires to their male partners.

\subsection{Women communication of sexual feelings to male partners}

Communication implies shared meanings and understanding. Participants understood the question well as demonstrated by their responses, which addressed the following questions: How do you make your partner know you are now hot: you are now ready for / wanted penetration; you are enjoying the heterosexual act; or you are approaching orgasm?

All participants talked of personal experiences of sexual desire and enjoyment of sexual interaction with their male partners. They believed that the sexual feelings they had for their male partners were "natural" and "something one is born with and dies with". One of the participants from the communal rural areas said, "We don't have to feel ashamed of sexual desire. Sexual desire is natural. It feels good even for the old. It just happens naturally for both men and women". This meant that participants believed that heterosexuality interest was not an artificial construction, but something women and men are born with. It just happens naturally for both women and men. This corroborates Muhanguzi's (2015) findings among low-income women in Uganda.

How did participants communicate their sexual feelings to their male partners? Although some, especially those from affluent suburbs, had given up on communicating their feelings to their male partners, the majority of participants endorsed Muhanguzi's (2015) findings that they 'expressed their sexual interest to their male partners using non-verbal expressions to signal love, affection and intimacy through establishing physical contact and closeness, caressing and kissing'. Some claimed that as far as luring their men to bed, it was not a big deal; they just seduced them through suggestive behaviour. "Men cannot resist sex, especially when they have already fallen for you", said one of the participants from the rural communal areas. Reaffirming Muhanguzi's (2015) findings in Uganda others reported 'getting the domestic chores done early; having meals together, being romantic', among other strategies. Some said they spoke out their feelings and desires. All this supports the view that women are not simply heterosexual passive objects, but they actively participate and express agency in their sexual relationships. They may not voice that they want sex today but they still tell the partner they want it anyway. This is in contradiction to some of the mainstream feminist arguments that heterosexuality makes women passive and submissive with limited choices of sexual expression and pleasure. What may be lacking here is overt expression 
of their desires and feelings, but the message gets to its destination and hits the target very well. To understand sexual behaviour we have to view it in its contextual totality. Otherwise, we risk making faulty conclusions.

\subsection{Can you survive without sex?}

The above question addressed the heterosexuality debate. As on the issue of communication above, answers to the above question from both affluent and communal women were almost similar. Therefore, we do not demarcate or give boundaries on the perceptions of the two groupings. Following are sample answers to the question from participants:

- Certainly not. Some people say sex was designed for procreation. I think they are wrong. Why does it taste so good if it was designed simply for reproduction purposes? Sex is sweet; I cannot do without sex.

- Penis is great. I like it. It makes me see heavens with joy. Even my husband knows that it makes me mad. When I want it, there are no negotiations. I simply demand it, and my husband obeys. There is nothing that tastes better than the penis.

- I like sex; especially when he comes from behind with my head heading the pillow, I forget everything else...

- Have you ever tried it after you have just said nasty things to each other? You end up holding to him tightly. Food does not get through after you have been scolded. Sex makes you forget everything.

- I am still new to sex. I am only 18, but that little experience has already told me that I cannot do without penis. I cannot explain the feeling. I really like it.

- We only whimper, chuckle, scream with pleasure, moan and have pregnant deep breathes and sighs during coitus. We do not do these things when having delicious food. Sex is a very nice experience. I do not think there is any normal person who can do without sex.

- Sex is the reason we marry. We leave our parents to stay with a stranger because of the penis. Otherwise, we would happily stay with our parents forever. Some would say they marry for children. That is covering up. You can have children whilst you stay alone. We marry because we want to be close to him.

These sentiments reaffirm Muhanguzi's (2015) findings that although we have a lot of diversity in terms of experiences with heterosexuality, women still want and enjoy heterosexual relationships in their own ways. In fact, participants of this study did not see their heterosexual relationships as oppressive, but regarded them as a natural phenomenon that fulfils their own inbuilt desires.

It is however, important to take note of exposure and socialisation issues here. Perhaps these women had not been exposed to any other forms of fulfilling their sexual desires like lesbianism, use of dolls, masturbation, among many others. Obama's grandmother summarised the issues at stake well when she said:

Much of what you say is true, Auma. Our women have carried a heavy lord. If one is a fish, one does not try to fly-one swims with other fish. One only knows what one knows. Perhaps if I were young today, I would have not accepted these things. Perhaps I would only care about my feelings, and falling in love. But that's not the world I was raised in. I only know what I have seen. What I have not seen doesn't make my heart heavy' (Obama, 1995)

\subsection{Is your male partner taking you through to orgasm?}

Although almost all participants from the two groups enjoyed sex with male partners, most of them, especially those from high-class urban centres, felt that their male partners were not sensitive to their sexual needs. In most cases, they were left hanging exposing them to extramarital affairs and extra-sexual relationships. Following are verbatim sentiments from the affluent WhatsApp group:

- Orgasm can only be attained with a man who is not selfish; one who knows how to handle a woman. Orgasm does not need someone who is too fast for nothing. It needs someone older and experienced please.

- The thing has no formula but still all women want to reach orgasm for satisfaction. Mine umm; the stomach is too big now. On top of that, he does not make effort to ensure that his penis enters me to its full length. Now I am indifferent, whatever happens is okay with me. I make sexual moans and fake orgasm to make him feel important, but nothing actually happens.

- Hiii, how then do you expect someone not to have extra-sexual relationships in such a situation?

- $\quad$ Kkkk, you are very lucky that he sleeps with you so that you fake those enjoyment moans. As for me, I have given up. I now occupy myself with knitting before going to sleep.

- It is true; we are really in trouble. Failure to reach orgasm leaves me in hunger of further penetration. This makes me dislike him. What then can we do girls?

- $\quad$ Sorry girls. I do understand your plight because we are in the same boat. Mine has a big stomach. He has BP. Works late into the night such that he arrives home after $8 \mathrm{pm}$ from Monday to Friday. I have a nice house but it does not bring me happiness. All our children are now at university except for the youngest 
one. I am now tempted to try Ben 10 [garden boy]; perhaps he will help me to reach orgasm.

- $\quad \mathrm{Kkkk}$, my friend, have you ever reached orgasm since you married him?

- Perhaps only once. I feel that I am almost there but then he just relieves himself and gets weak leaving me hanging in the air. I now hate sex.

- Where is this problem of making us women fail to reach orgasm coming from girls? Can someone answer me so that we help each other to rectify the problem? I think even the girlfriend just fakes enjoyment moans just to make him feel important and get rid of him.

- I think it is partly because of our culture that does not allow us to open up to our husbands about how we want them to touch us. Also the husbands themselves are not taught how to handle women; how to caress their clitoris; how to touch and suck breasts; and so on. Once they are taught these things, you will all reach orgasm before they even penetrate you. Unfortunately, most of them are selfish. They also lack exercise making their stomachs bulge unnecessarily.

- You have said it all my friend. I give you 105\%. These husbands of ours make us angry. Some of us just stay with them for personal integrity, showing off to colleagues at church; these big cars and houses. Otherwise, we would have already gone back to our parents. All my children are already grown up but I still want penis penetration. My vagina kicks out craving for proper penetration but husband zero.

- You are lucky if yours still have strong erection. ...

They went on discussing the issue:

- $\quad$ asking those who reach orgasm how they do it;

- claiming that there is no way they can enjoy the sweetness of the penis without reaching orgasm;

- disclosing that they fake enjoyment moans and sighs;

- justifying and praising extra-sexual relationships;

- $\quad$ asking how their parents were able to satisfy their polygamous families when their spouses were failing one woman;

- claiming that they were sailing in the same boat with their husbands' girlfriends;

- disclosing that they no longer respected their male partners because they were failing them in bed;

- regretting wasting their time doing clitoris elongation;

- $\quad$ disclosing that some of their husbands no longer had strong erections; and

- $\quad$ encouraging each other to try the Ben 10s (garden boys).

Reading between the lines of what the above women said, participants were of the view that heterosexual enjoyment and satisfaction can only be attained where the two parties are sensitive to the needs of each other. These women are not saying heterosexuality is bad. They like it, but their spouses are not performing up to standard forcing some of them to think of extra-sexual relationships.

\section{Conclusions}

This study validates the claims of mainstream feminist scholars like for example the claim that in heterosexual unions there are two marriages-his and hers (Bernard, 2002). In addition, the study endorses the claim that heterosexuality is oppressive and sometimes not sensitive to women needs (Butler, 1990; Vance, 1992; FaustoSterling, 2003; 2005; Amfred, 2004; Singh, 2013). We also established that men want sex more than the person herself (Langford, 2002) and that women fake orgasm (Duncombe and Marsden, 2002) as sexual activity declines and romance fades with time (Duncombe and Marsden, 2002). This study also found out that women simply give in to sexual penetration to please men (Holland, Ramazanoglu and Thompson, 2002).

Nevertheless, all this is half the story. The study went further to agree with those who argue that power inequality in relationships does not automatically exclude enjoyable and pleasurable sexual experiences (Jackson, 1996; Shefer and Foster, 2001; Bhana, 2013). Penetrative sex with men can be enjoyable; its pleasure for women is not merely eroticised submission (Segal, 1994; Van Every, 1996). As argued by Bhana (2013), relations should not only be perceived in terms of male power; men and women as gendered persons express love alongside the daily battles of power; and as presented by Rasool (2013) women have capacity to contest and shape their lives as they reflect on violent love. The study also established that contrary to Maitra and Schensul's (2002) claims that women in communal rural areas do not desire sex and as a result do not reach orgasm, in this study they desired sex and were most likely to reach orgasm than their colleagues in affluent residential areas. We therefore conclude that women are not just victims of romantic love but find spaces to negotiate their identity, as they navigate their economic circumstances (Herlihy, 2013).

In this paper, we argued that the heterosexual drive is biological and natural for most women and men. The need, however, can be satisfied through a variety of innovations and artificial means but this does not stop it from being biological and natural. We argue that the fact that like any other human scenario and experience, heterosexuality performance is multifaceted and has been facing human / artificial modifications the same way food is modified to enhance its taste does not stop heterosexuality from being largely a biological and physiological 
need. Hunger is either silenced with manna from heaven or some edible natural organic matter, which has been exposed to artificial innovation, but this does not stop it from being physiological and natural. Without food, there is no life the same way life faces extinction without heterosexuality. People consume food to satisfy both survival and recreation / leisure needs the same way they indulge in sex for the satisfaction of both human survival and recreation / leisure needs.

\section{Recommendations for further studies.}

The study established that sexuality is multifaceted and contextual. It also established that for women orgasm is not easy to attain. We, therefore recommend further studies on factors influencing women attainment or lack of attainment of orgasm.

\section{References}

Bernard, J. (2002). 'The husband's marriage and the wife's marriage'. In S. Jackson and S. Scott. (eds). (2002). Gender: A sociological reader. London. Routledge.

Bhana D. (2013). Introducing love: gender, sexuality and power. Agenda. 27(2): 3-11.

Butler, J. (1990). "Performative acts and gender constitution", in Performing feminisms. S-E. Case (ed.), Baltimore: John Hopkins University.

Duncombe, J. and Marsden, D. (2002). 'Whose orgasm is this anyway? Sex work in long-term heterosexual couple relationships'. In S. Jackson and S. Scott. (eds). (2002). Gender: A sociological reader. London. Routledge.

Epprecht, M. (2013). Hungochani: The history of a dissident sexuality in southern Africa (2nd ed.) Montreal, Quebec: McGill-Queen's Press-MQUP.

Fausto-Sterling, A. (2003). "The problem with sex/gender and nature/nurture", in Williams, S.J. Birke, L. and Bendelow, G.A. (eds.). Debating biology: Sociological reflections on health, medicine and society. London \& New York: Routledge.

Fausto-Sterling, A. (2005). "The bare bones of sex: Part 1 - sex and gender", Signs, 30: 1491-1527.

Government of Zimbabwe. (2013). Amendment (No. 20) Act (2013). Harare: Fidelity Printers and Refiners.

Herlihy L.H. (2013). The discourse of romantic love on the Miskitu coast. Agenda. 27: 76-85.

Hirsch J.S. (2007). The inevitability of infidelity: sexual reputation, social geographies, and marital HIV risk in rural Mexico. American Journal of Public Health. 97(6): 986-996.

Holland, J., Ramazanoglu, C and Thompson, R. (2002). 'In the same boat'. In S. Jackson and S. Scott. (eds). (2002). Gender: A sociological reader. London. Routledge.

Ingraham, C. (2002). 'The heterosexual imaginary'. In S. Jackson and S. Scott. (eds). (2002). Gender: A sociological reader. London. Routledge. Pp. 79-84.

Jackson S. (1996). Heterosexuality and feminist theory. In Richardson. (editor). Theorising heterosexuality: Telling it straight. Philadelphia: Open University Press.

Jackson, S. and Scott, S. (eds). (2002). Gender: A sociological reader. London. Routledge.

Langford, W. (2002). 'But he said he loved me'. In S. Jackson and S. Scott. (eds). (2002). Gender: A sociological reader. London. Routledge.

Maitra S, Schensul S.L. (2002). Reflecting diversity and complexity in marital sexual relationships in a low income community in Mumbai. Culture, Health and Sexuality. 4(2): 133-151.

Mapuranga, B. (2019). Sexual and reproductive rights of women with disabilities in Zimbabwe: A study of public policy and practice in Harare: PhD thesis. Harare. Zimbabwe Open University.

Muhanguzi, F.K. (2015) "Sex is sweet": women from low-income contexts in Uganda talk about sexual desire and pleasure. Reproductive Health Matters. 23:46, 62-70,

Obama, B. (1995). Dreams from my father: A story of race and inheritance. New York. Crown.

Peta, C. (2015). Voices from the periphery: a narrative study of the experiences of sexuality of disabled women in Zimbabwe: PhD thesis. Cape Town. University of Cape Town.

Rasool S. (2013). Reconstructing discourses of love to facilitate help seeking after woman abuse. Agenda. 27(2): $56-64$.

Segal L. (1994). Straight sex: The politics of pleasure. London. Virago.

Shefer, T. and Foster, D. (2001). Discourses on women's heterosexuality and desire in a South African local context. Culture, Health and Sexuality. 3(4): 375-390.

Singh S. (2013). Women want love, men want wives: The discourse of romantic love in young adults' future marriage goals. Agenda. 27(2):22-29.

Vance C. (1992). 'Pleasure and danger: Toward politics of sexuality'. In C. Vance. (ed). Pleasure and desire: Exploring female sexuality. London: Pandora Press.

Van Every J. (1996). Heterosexuality and domestic life. In Richardson. (editor). Theorising heterosexuality: Telling it straight. Philadelphia: Open University Press.

Zinanga, E. (1996). Sexuality, identity and change. Southern Africa Feminist Review, 2(1), 36. 